\title{
Hospital-Wide Interprofessional Simulation-Based Training in Crisis Resource Management
}

\author{
Jameel Abualenain ${ }^{1,2,3}$ (i) \\ 'Department of Emergency Medicine, King Abdulaziz University Faculty of Medicine, Jeddah, Saudi Arabia \\ ${ }^{2}$ Clinical Skills and Simulation Center, King Abdulaziz University Faculty of Medicine, Jeddah, Saudi Arabia \\ ${ }^{3}$ Department of Emergency Medicine, George Washington University, Washington, D.C, United States of America
}

Cite this article as: Abualenain J. Hospital-Wide Interprofessional Simulation-Based Training in Crisis Resource Management. Eurasian J Emerg Med. 2018; 17 (3): 93-6.

\begin{abstract}
Aim: Crisis resource management (CRM) refers to the set of non-technical skills such as leadership, task distribution, communication, anticipation, calling for help, and workload distribution required during crisis for effective teamwork. Currently, there is no formal training for healthcare workers at King Abdulaziz University Hospital (KAUH). The leaders of KAUH along with those of the Clinical Skills \& Simulation Center sought to develop a simulation-based training program as a continuous effort to improve interprofessional training and patient safety.
\end{abstract}

Materials and Methods: In this quasi-experimental study, we developed a simulation-based program consisting of four phases: Needs assessment via mock codes, "Train the Trainer" course, CRM courses, and post-program evaluation via mock codes. Pre-tests and post-tests were performed in each course.

Results: Phase one: Twenty-five healthcare workers participated in four mock codes; using an internally developed checklist, the average score was $46 \%$ of checklist items. Phase two: Eighteen potential instructors attended the "Train the Trainer" course, and average pre-test and post-test scores were $31 \%$ and $61 \%$, respectively. Ten instructors participated in the following courses. Phase three: Ten CRM courses conducted for 184 healthcare workers with different backgrounds. Pre-test and post-test cumulative scores were $48 \%$ and $64 \%(p=0.0008)$, respectively. Phase four: average score for all four mock codes was $76 \%$ compared to $46 \%$ in the needs assessment phase $(p=0.0003)$.

Conclusion: Simulation-based training is an effective tool for the application of CRM principles. It might lead to improvements in patient safety and reduction in human errors. An organization's leadership is essential to ensure the successful implementation of the program.

Keywords: Simulation, crisis resource management, interprofessional training

\section{Introduction}

Crisis resource management (CRM) principles were introduced in the 1970 s in the aviation industry in response to the alarming fact that approximately $70 \%$ of airplane crashes happened because of teamwork failure and human errors (1-3). Anesthesia was the first medical specialty to adopt the CRM principles and bring them to the healthcare industry to mitigate human errors and improve teamwork $(4,5)$. Emergency medicine followed the same path and introduced CRM for its physicians and trainees (6-9). CRM refers to the set of non-technical skills and behavioral principles such as leadership, task distri- bution, communication, knowledge of environment, anticipation and planning, obtaining timely assistance, attention allocation, and workload distribution (4-9) required during crisis for effective teamwork. The Institute of Medicine recommends the use of simulation in interdisciplinary team training to improve patient safety (10).

The Clinical Skills and Simulation Center (CSSC) at the King Abdulaziz University Hospital (KAUH) is a well-known simulation-based training center both nationally and in the Middle East. It was recently internationally accredited by two prestigious bodies in the field of simulation: The Royal College of Physicians and Surgeons of Canada

ORCID ID of the author: J.A. 0000-0003-4623-7292.

Corresponding Author: Jameel Abualenain e-mail: jameel.abualenain@gmail.com 
and Society for Simulation in Healthcare. In addition, CSSC awarded KAUH with the ASPIRE trophy for "Excellence in Simulation" at the Association for Medical Education in Europe's (AMEE) 2017 International Conference in Medical Education in Finland.

King Abdulaziz University Hospital did not have a formal interprofessional CRM training for healthcare workers (HCWs). This issue was recognized during the risk management and quality improvement executive meetings, which received reports from the cardiopulmonary resuscitation (CPR) committee that there is scope for improvement in the non-technical skills during resuscitation and rapid response situations. Hence, KAUH leaders along the CSSC leaders sought to develop a simulation-based CRM training program for all HCWs in $\mathrm{KAUH}$ as continuous efforts to improve patient safety and mitigate human errors during crisis and critical situations.

\section{Materials and Methods}

This is a quasi-experimental (pre-test and post-test) study that was conducted in 2016 in the CSSC at KAUH located in Jeddah, Saudi Arabia. Initially, an interdisciplinary committee was formed (ten members: six physicians and four nurses) to develop the CRM program under the guidance of KAUH and CSSC leadership. The committee met a couple of times until they developed the structure of the program and the implementation plan. Ethics committee approval was received for this study from the Unit of Biomedical Ethics at King Abdulaziz University, School of Medicine (Reference No. 378-16, 2016). As with any other activity that takes place in the CSSC, all the participants in the program signed confidentiality agreements, and consented to participate as per the CSSC policy and procedures.

The CRM program consisted of four phases. Phase One: Needs assessment. This was done by running four mock codes in different areas of the hospital: the emergency department (ED) and hospital wards. The cases were two patients with CPR (unresponsive patient with no palpable pulse and apneic) and two critically ill patients (septic shock and gastrointestinal active bleeding) consisting of two adults and two children. We developed a checklist that addressed the main CRM principles. The listed ten items were based on what has been mentioned in the literature (4-6). It included: know the environment, effective leadership, effective communication (closedloop), good teamwork, call for help, frequent re-evaluation, sharing information, workload distribution, utilization of available resources, and allocate attention wisely (avoid fixation error). The checklist was used together with the standard KAUH checklist for a Code Blue resuscitation.

Phase Two: "Train the Trainer" Course. This was a one-time course to develop CRM course instructors. The participants in this course were personally selected by the CSSC leaders from different specialties. The selection was based on prior knowledge of the candidates' skills in teaching and experience with simulation training. The course focused on the essential skills of simulation-based training, basic debriefing, and the CRM principles. In addition, candidates underwent two high-fidelity simulation scenarios that were then followed by a group debriefing. The scenarios and the debriefing focused mainly on the CRM principles. Written pre-tests and post-tests were also conducted.
Phase Three: CRM courses for HCWs. In this phase, invitations were sent to all clinical department heads, including the nursing department, of the hospital. The invitations listed the dates for the CRM courses, and encouraged each department to send their HCWs to attend the CRM course on any of the assigned dates. The CSSC was responsible to balance the list of participants to have enough physicians to be able to run the scenarios in a realistic way that mimics real patient encounters. The CRM course objectives focused on introducing the CRM principles and human errors. The course started with theories, and then was followed by four stations. Each has an internally peer-reviewed scenario involving crisis clinical situation. The scenarios were run using high-fidelity simulators. All stations were followed by a debriefing using a video recording to assist in the discussion and reflection. The courses were directed and instructed by the CSSC leaders who are simulation experts, and who have received formal postgraduate training in simulation. Additionally, ten co-instructors from the "Train the Trainer" course participated in the course instructions. Written pre-tests and post-tests were conducted in addition to the course evaluation.

Phase Four: Post-program evaluation. After conducting ten courses, the program organizing committee decided to evaluate the impact of these courses on the ground. Around one month after the last course, four mock codes took place on different occasions in the ED and hospital wards. The cases were two patients with CPR and two critically ill patients-two adults and two children. The same checklist was used to evaluate team performance in the CRM principles.

\section{Statistical analysis}

Data coding was carried out manually and analyzed using Stata Version 13.0 (Stata Corp, College Station, Texas, USA). The descriptive analysis of the quantitative data for categorical variables was presented by frequencies and percentages. Paired t-test was used to assess the difference between pre-test and post-test among participants. The significance level was set at $\mathrm{p} \leq 0.05$.

\section{Results}

Phase One: A total of $25 \mathrm{HCWs}$ participated during the care of the four mock codes; 13 were from the $E D$, four were from the intensive care unit (ICU), 4 were from Internal Medicine, and four were from Pediatrics. Scores for the four mock codes were $50 \%, 45 \%, 45 \%$, and $45 \%$ of the checklist items. The average score for all four codes was $46 \%$ (Figure 1).

Phase Two: Eighteen potential CRM instructors participated in the "Train the Trainer" course. The group had 61\% male with 11 physicians, five nurses, and two others. Seven participants were from the $E D$, four were from Anesthesia, five were from Nursing, and two were technicians. The average pre-test and post-test scores were 31\% (10$50 \%$ ) and $61 \%(40-80 \%)$, respectively. From the 18 participants, 10 joined as instructors at least once in subsequent courses, and five became regularly involved.

Phase Three: Ten courses were conducted during the study period. The total number of participants was 184; 73\% were female, and 106 $(58 \%)$ were nurses. A total of 58 physicians from different specialties attended the courses. The detailed characteristics of HCWs who at- 


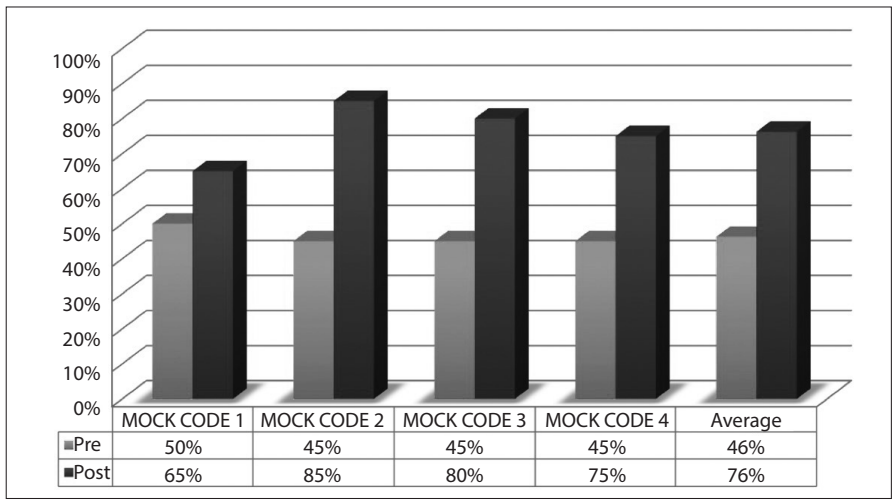

Figure 1. Pre and Post program evaluations of the 4 Mock codes conducted in the different hospital areas. (\%) Is the percent (average) of satisfactory items checked in the checklist by two reviewers

Table 1. Characteristics of healthcare workers who participated in the 10 courses

\begin{tabular}{|l|c|}
\hline & $\mathbf{n = 1 8 4}(\%)$ \\
\hline Female & $\mathbf{1 3 5}(\mathbf{7 3} \%)$ \\
\hline Physicians & $\mathbf{5 8}(\mathbf{3 2} \%)$ \\
\hline Emergency Medicine & $27(47 \%)$ \\
\hline Anesthesia & $13(22 \%)$ \\
\hline Surgery & $8(14 \%)$ \\
\hline Intensive Care Unit & $6(10 \%)$ \\
\hline Internal Medicine & $4(7 \%)$ \\
\hline Nurses & $\mathbf{1 0 6}(\mathbf{5 8 \% )}$ \\
\hline Ward, clinics, and non-critical & $75(71 \%)$ \\
\hline Critical Care & $22(21 \%)$ \\
\hline Emergency Department & $9(8 \%)$ \\
\hline Technicians & $\mathbf{2 0 ( 1 1 \% )}$ \\
\hline Paramedics & $9(45 \%)$ \\
\hline Anesthesia Tech. & $5(25 \%)$ \\
\hline Others & $6(30 \%)$ \\
\hline
\end{tabular}

tended these ten courses are shown in Table 1. Pre-test and post-test cumulative scores for the participants in the ten courses improved significantly $(p=0.0008)$ and were $48 \%(64-28 \%)$ and 64\% (53-74\%), respectively.

Phase Four: Scores of the four mock codes post-program were $65 \%$, $85 \%, 80 \%$, and $75 \%$ of the checklist items. The average score for all four codes improved significantly $(p=0.0003)$ compared to the needs assessment phase (76\% vs. 46\%) (Figure 1).

\section{Discussion}

Team failures and human errors continue to occur in the healthcare sector, which results in unfortunate medical errors, and thus places a huge burden on healthcare system (10). In this study, we provided interprofessional CRM simulation-based training for more than 200 HCWs from different backgrounds and different experiences within the same institution. We were able to improve the knowledge and team performance in applying the CRM principles during crisis situations. This was evident in the post-tests after each course and the post-program evaluations.

The literature clearly supports simulation's impact on team performance and competency in numerous works. However, we still struggle to conduct works that show measurable impacts on patient safety and outcomes (11-14). Conducting CRM training programs for HCWs on this scale and sustaining training operations could be effective ways to mitigate human error and improve patient safety in the medical field. Establishing a training program that targets all HCWs in an institution is a difficult task. Leadership at different levels in $\mathrm{KAUH}$ and CSSC had to come together to launch and support a simulation-based training that focuses on the CRM principles at the hospital level. One of the biggest obstacles to this program was recruiting participants and freeing them from their duties to attend a full-day simulation course. More challenging than the implementation of such a program is the sustainability to keep the momentum and to ensure continuous effect, which we are still striving to achieve.

\section{Study limitations}

The limitations of this work include the fact that we only covered about $8 \%$ to $10 \%$ of our HCWs. However, the focus was on the HCWs working in critical areas (ED, ICU, or anesthesia). Outcomes related to patient morbidity, mortality, or decrease in medical errors need to be studied to determine whether a higher level in Kirkpatrick's model can be achieved (15).

\section{Conclusion}

Applying CRM principles is crucial for effective teamwork during crisis situations, which can lead to improved patient safety and decreased human errors. The lack of formal training in CRM among HCWs can be addressed by conducting interprofessional simulation-based training courses by simulation experts. Investing in developing CRM instructors with different backgrounds within the organization is of great value. Developing a simulation-based training program requires joint effort from the organization's leadership.

Ethics Committee Approval: Ethics committee approval was received for this study from the Ethics Committee of the Unit of Biomedical Ethics at King Abdulaziz University, Faculty of Medicine (Approval No.: 378-16, 2016).

Informed Consent: Written informed consent was waived by the ethical committee because all data were deidentified and no identifiable participants' information was collected or utilized during the study.

Peer-review: Externally peer-reviewed.

Acknowledgements: The author extends his appreciation to The Supervisor of the Clinical Skills \& Simulation Center (CSSC) Professor Abdulaziz Boker for his invaluable and unlimited support. Moreover, I am appreciative to Dr Abeer Arab, Mr Jamal Alshorman, and Mr Mohammed Almalki from the CSSC at King Abdulaziz University for their support and assistance. Additionally, I am grateful to Dr Amro Ahibshi, Dr Shadi Alkhayyat, Mrs Laila Altabsh, \& Mrs Abeer Al hazmi from King Abdulaziz University Hospital for their support and assistance. 
Conflict of Interest: The author has no conflict of interest to declare.

Financial Disclosure: This work was supported by King Abdulaziz University Hospital. The author did not receive any type of commercial support for this study. The author has no financial interest in any of the products or devices, mentioned in this article.

\section{References}

1. Wiener EL, Kanki BG, Helmreich RL, editors. Cockpit Resource Management. New York: Academic Press, 1993.

2. Fisher J, Phillips E, Mather J. Does crew resource management training work? Air Med J. 2000; 19: 137-9. [CrossRef]

3. Helmreich RL. Does CRM training work? Air Line Pilot. 1991; 60: 17-20.

4. Howard SK, Gaba DM, Fish KJ, Yang G, Sarnquist FH. Anesthesia crisis resource management training: teaching anesthesiologists to handle critical incidents. Aviat Space Environ Med. 1992; 63: 763-70.

5. Gaba DM, Howard SK, Fish KJ, Smith BE, Sowb YA. Simulation-based training in anesthesia crisis resource management (ACRM): a decade of experience. Simul Gaming. 2001; 32: 175-93. [CrossRef]

6. Reznek M, Smith-Coggins R, Howard S, Kiran K, Harter P, Sowb Y, et al. Emergency Medicine Crisis Resource Management (EMCRM): Pilot study of a simulation-based crisis management course for emergency medicine. Acad Emerg Med. 2003; 10: 386-9. [CrossRef]
7. Hicks CM, Bandiera GW, Denny CJ. Building a Simulation-based Crisis Resource Management Course for Emergency Medicine, Phase 1: Results from an Interdisciplinary Needs Assessment Survey. Acad Emerg Med. 2008; 15: 1136-43. [CrossRef]

8. Carne B, Kennedy M, Gray T. Review article: Crisis resource management in emergency medicine. Emerg Med Australas. 2012; 24: 7-13. [CrossRef]

9. Cheng A, Donoghue A, Gilfoyle E, Eppich W. Simulation-based crisis resource management training for pediatric critical care medicine: a review for instructors. Pediatr Crit Care Med. 2012; 13: 197-203. [CrossRef]

10. Kohn LT, Corrigan JM, Donaldson MS, editors. To Err is Human: Building a Safer Health System. Washington, DC: National Academy Press, 1999.

11. Nishisaki A, Keren R, Nadkarni V. Does simulation improve patient safety?: self-efficacy, competence, operational performance, and patient safety. Anesthesiol Clin. 2007; 25: 225-36. [CrossRef]

12. Zendejas B, Brydges R, Wang AT, Cook DA. Patient outcomes in simulation-based medical education: a systematic review. J Gen Intern Med. 2013; 28: 1078-89. [CrossRef]

13. Lorello GR, Cook DA, Johnson RL, Brydges R. Simulation-based training in anaesthesiology: a systematic review and meta-analysis. Br J Anaesth. 2014; 112: 231-45. [CrossRef]

14. Baker DP, Salas E, King H, Battles J, Barach P. The role of teamwork in the professional education of physicians: current status and assessment recommendations. Jt Comm J Qual Patient Saf. 2005; 31: 185-202. [CrossRef]

15. Kirkpatrick DL, Kirkpatrick JD, editors. Evaluating Training Programs: the four levels. San Francisco: Berrett-Koehler Publishers. 1994.p.36-48. 